\title{
Separating Bayesian Updating from Non-Probabilistic Reasoning: An Experimental Investigation
}

Dan Levin, James Peck, and Asen Ivanov

\section{Online Appendix: Instructions and Screen Shots}

After being shown pictures of both sides of each of the cards, the subjects answered the following questions on their computer screens:

Situation 1. From two cards, black-black or black-white, we randomly selected one card and then randomly selected which side to be face up. You can see the face-up side of this card on your screen. Please give your best assessment of the probability that the face-down side is black, by typing a number between 0 and 100 in the box below, and clicking OK. For example, the number 40 corresponds to a $40 \%$ chance that the face-down side is black, or a probability of 0.40 , the number 60 corresponds to a $60 \%$ chance that the face-down side is black, or a probability of 0.60 , and so on.

Your earnings will be based on how close your number is to the mathematically correct percentage. If your number equals the correct percentage or is off by no more than 1, you will receive $10 \mathrm{ECU}$; if your number is off from the correct percentage by more than 1 but is within 5 , you will receive 5 ECU; otherwise, you will receive 0 ECU.

Situation 2. Once again, from two cards, black-black or black-white, we randomly selected one card and then randomly selected which side to be face up. Suppose that a mathematically sophisticated player who currently does not see the face-up side must guess whether the face-down side is black or white, and will be paid 60 Euros if her guess is correct. We are asking you to determine the maximum amount that she would be willing to pay for the certain knowledge of the face-up side of the card. Please give your best assessment of how much the sophisticated player would value the information of the face-up side (in Euros), by typing a number between 0 and 60 in the box below, and clicking OK. 
Your earnings will be based on how close your number is to the mathematically correct calculation. If your number equals the correct value of the information, or is off by no more than 1, you will receive 10 ECU; if your number is off from the correct calculation by more than 1 but is within 5 , you will receive 5 ECU; otherwise, you will receive 0 ECU.

Situation 3. From three cards, black-black or black-white or white-white, we randomly selected one card and then randomly selected which side to be face up. You can see the face-up side of this card on your screen. Please give your best assessment of the probability that the face-down side is black, by typing a number between 0 and 100 in the box below, and clicking OK. For example, the number 40 corresponds to a $40 \%$ chance that the face-down side is black, or a probability of 0.40 , the number 60 corresponds to a $60 \%$ chance that the face-down side is black, or a probability of 0.60 , and so on.

Your earnings will be based on how close your number is to the mathematically correct percentage. If your number equals the correct percentage or is off by no more than 1, you will receive $10 \mathrm{ECU}$; if your number is off from the correct percentage by more than 1 but is within 5 , you will receive 5 ECU; otherwise, you will receive 0 ECU.

Situation 4. Once again, from three cards, black-black or black-white or white-white, we randomly selected one card and then randomly selected which side to be face up. Suppose that a mathematically sophisticated player who currently does not see the face-up side must guess whether the face-down side is black or white, and will be paid 60 Euros if her guess is correct. We are asking you to determine the maximum amount that she would be willing to pay for the certain knowledge of the face-up side of the card. Please give your best assessment of how much the sophisticated player would value the information of the face-up side (in Euros), by typing a number between 0 and 60 in the box below, and clicking OK.

Your earnings will be based on how close your number is to the mathematically correct calculation. If your number equals the correct value of the information, or is off by no more than 1, you will receive $10 \mathrm{ECU}$; if your number is off from the correct calculation by more than 1 but is within 5 , you will receive 5 ECU; otherwise, you will receive 0 ECU. 


\section{Auction Instructions for $A D$ Treatment}

1. We will now create a market in which you will act as buyers of a fictitious commodity in a sequence of trading periods. A single unit of the commodity will be auctioned off in each trading period. There will be several trading periods.

2. At the start of each period, participants are randomly placed into "markets" containing six (6) participants. If the number of available participants is not an exact multiple of six, there will be a small number of participants that are not placed in a market and who will sit out until the next period.

The random assignment of participants to markets will be done separately and independently for each period. This means that the chances that you and any given other participant are in the same market in the current period do not depend on whether the two of you were in the same market in previous periods. Rarely, this randomization procedure can have the same participant sit out for two or more consecutive periods.

3. Your task is to bid for the commodity in competition with the other five buyers in your market. In each period, the computer will select a RESALE VALUE for the unit being auctioned. This indicates the value to you of purchasing the unit in your market. This value may be thought of as the amount you would receive if you were to resell the unit. The process of determining resale values and your signals regarding resale values will be described in Sections 6 and 7 below.

4. In the middle of the screen, you will see a rectangular clock displaying a price in ECUs, which we refer to as the "Clock Price." In each new period, the market will begin with the clock displaying a Clock Price of 250 ECU. Then, after the market begins, for every half-second that passes, the Clock Price will decrease by 1 ECU. To express your willingness to purchase the unit at the current Clock Price, you must click the button labeled Purchase located beside the clock. The Clock Price at which you click Purchase will be referred to as your bid.

The clock will continue to tick down until the first moment that one of the participants in your market clicks Purchase. At this point, the clock will stop, and the participant who clicked Purchase will be the one to purchase the unit. The price displayed as the Clock Price at the time when that participant clicked Purchase will be the Market Price for that period. 
In the event two or more participants in the same market click the Purchase button at the same price (i.e., a tie), one of the tying participants will be chosen at random to purchase the unit at that Market Price.

If no participant in a given market has clicked Purchase when the Clock Price reaches zero, then no participant in that market will purchase the unit of the commodity.

5. Those participants that do not purchase the item in a given period receive a Profit of zero for that trading period. The participant that purchases the item receives a Profit given by

$$
\text { Profit }=\text { Resale Value }- \text { Market Price. }
$$

Profits earned during a trading period will be added to the purchaser's Cash Balance, and losses incurred will be subtracted from the purchaser's Cash Balance. Remember, your goal should be to maximize your profits, not the number of times you outbid the other participants.

If your Cash Balance falls below zero, you will not be allowed to continue participating. However, you are permitted to bid in excess of your Cash Balance in any given period.

6. For each market, the Resale Value will be a randomly drawn number between $25 \mathrm{ECU}$ and $225 \mathrm{ECU}$. Any value within this range has an equally likely chance of being drawn, and all randomizations are done all over again for each trading period.

7. Participants are NOT told the Resale Value in their market. However, at the beginning of each trading period, each participant will receive a Signal (which may be regarded as an estimate), that may provide information about the Resale Value in her/his market. Your signal will be randomly chosen between: a lower bound equal to the Resale Value minus 24, and an upper bound equal to the Resale Value plus 24. For example, if the Resale Value is 75 , then every participant in this market will receive a signal that is between 51 and 99. All signals in this interval are equally likely to be received, and a separate (and independent) randomization is done for each participant. That is, although all participants in the same market will face the same Resale Value, their signals that are generated in the way we have just described will usually be different. 
Notice that you might receive a signal below $25 \mathrm{ECU}$ or above $225 \mathrm{ECU}$. There is nothing strange about this; it just indicates that the Resale Value is either close to 25 ECU or close to 225 ECU.

8. Your signal will be displayed on your screen above the clock. This signal is strictly private information and is not to be revealed to anyone else. You are not to look at anyone else's screen or speak to any other participant while the experiment is in progress. This is important to the validity of the study.

9. As we mentioned earlier, Resale Values are determined randomly and independently from period to period. As such, a high value in one period tells you nothing about whether it might be high or low in the next period. Since a similar independent random process determines the signals, your signal in one period tells you nothing about signals or the Resale Value in later periods.

10. Information on the Computer Screen. At the beginning of each period, the top of the computer screen will show your ID number, your current Cash Balance, and the period number. In the middle of the screen, you will see your signal and the only possible Resale Values consistent with your signal. When everyone has clicked the Continue button, you will see a screen with the clock showing the initial Clock Price of 250 ECU. To the right of the clock will appear the Purchase button, and above the clock your signal for that period will be displayed. The auction will begin soon after seeing this screen, so you should plan your strategy when you first see your signal.

After each trading period is over, you will see a screen that summarizes the auction you just finished, showing: the Market Price, the Resale Value, the highest bidder's profit or loss, your profit or loss, your Cash Balance entering the period, and your current Cash Balance. Towards the bottom of the screen, you will see your signal, the signal of the participant who submitted the highest bid, and the signals of all buyers in your market. When all participants have clicked Continue, we proceed to the next period.

11. We will start with three or four practice "dry runs" that do not count towards your earnings, at which point we will stop and answer any additional questions.

Are there any questions? 


\section{Auction Instructions for $S D$ treatment}

1. We will now create a market in which you will act as buyers of a fictitious commodity in a sequence of trading periods. A single unit of the commodity will be auctioned off in each trading period. There will be several trading periods.

2. At the start of each period, participants are randomly placed into "markets" containing six (6) participants. If the number of available participants is not an exact multiple of six, there will be a small number of participants that are not placed in a market and who will sit out until the next period.

The random assignment of participants to markets will be done separately and independently for each period. This means that the chances that you and any given other participant are in the same market in the current period do not depend on whether the two of you were in the same market in previous periods. Rarely, this randomization procedure can have the same participant sit out for two or more consecutive periods.

3. Your task is to bid for the commodity in competition with the other five buyers in your market. In each period, the computer will select a RESALE VALUE for the unit being auctioned. This indicates the value to you of purchasing the unit in your market. This value may be thought of as the amount you would receive if you were to resell the unit. The process of determining resale values and your signals regarding resale values will be described in Sections 6 and 7 below.

4. In the middle of the screen, you will see a rectangular clock displaying a price in ECUs, which we refer to as the "Clock Price." In each new period, the market will begin with the clock displaying a Clock Price of 250 ECU. Then, after the market begins, for every half-second that passes, the Clock Price will decrease by 1 ECU. To express your willingness to purchase the unit at the current Clock Price, you must click the button labeled Purchase located beside the clock. The Clock Price at which you click Purchase will be referred to as your bid.

The clock will continue to tick down until you bid or the Clock Price reaches 0. At that point, the results of the market will be displayed. The participant in each market who first clicked Purchase, and therefore clicked at the highest price, will be the one to purchase the unit. The price displayed as the Clock Price at the time when that participant clicked Purchase will be the Market Price for that period. 
In the event two or more participants in the same market click the Purchase button at the same price (i.e., a tie), one of the tying participants will be chosen at random to purchase the unit at that Market Price.

If no participant in a given market has clicked Purchase when the Clock Price reaches zero, then no participant in that market will purchase the unit of the commodity.

5. Those participants that do not purchase the item in a given period receive a Profit of zero for that trading period. The participant that purchases the item receives a Profit given by

$$
\text { Profit }=\text { Resale Value }- \text { Market Price. }
$$

Profits earned during a trading period will be added to the purchaser's Cash Balance, and losses incurred will be subtracted from the purchaser's Cash Balance. Remember, your goal should be to maximize your profits, not the number of times you outbid the other participants.

If your Cash Balance falls below zero, you will not be allowed to continue participating. However, you are permitted to bid in excess of your Cash Balance in any given period.

6. For each market, the Resale Value will be a randomly drawn number between $25 \mathrm{ECU}$ and $225 \mathrm{ECU}$. Any value within this range has an equally likely chance of being drawn, and all randomizations are done all over again for each trading period.

7. Participants are NOT told the Resale Value in their market. However, at the beginning of each trading period, each participant will receive a Signal (which may be regarded as an estimate), that may provide information about the Resale Value in her/his market. Your signal will be randomly chosen between: a lower bound equal to the Resale Value minus 24, and an upper bound equal to the Resale Value plus 24. For example, if the Resale Value is 75 , then every participant in this market will receive a signal that is between 51 and 99. All signals in this interval are equally likely to be received, and a separate (and independent) randomization is done for each participant. That is, although all participants in the same market will face the same Resale Value, their signals that are generated in the way we have just described will usually be different. 
Notice that you might receive a signal below $25 \mathrm{ECU}$ or above $225 \mathrm{ECU}$. There is nothing strange about this; it just indicates that the Resale Value is either close to 25 ECU or close to 225 ECU.

8. Your signal will be displayed on your screen above the clock. This signal is strictly private information and is not to be revealed to anyone else. You are not to look at anyone else's screen or speak to any other participant while the experiment is in progress. This is important to the validity of the study.

9. As we mentioned earlier, Resale Values are determined randomly and independently from period to period. As such, a high value in one period tells you nothing about whether it might be high or low in the next period. Since a similar independent random process determines the signals, your signal in one period tells you nothing about signals or the Resale Value in later periods.

10. Information on the Computer Screen. At the beginning of each period, the top of the computer screen will show your ID number, your current Cash Balance, and the period number. In the middle of the screen, you will see your signal and the only possible Resale Values consistent with your signal. When everyone has clicked the Continue button, you will see a screen with the clock showing the initial Clock Price of 250 ECU. To the right of the clock will appear the Purchase button, and above the clock your signal for that period will be displayed. The auction will begin soon after seeing this screen, so you should plan your strategy when you first see your signal.

After each trading period is over, you will see a screen that summarizes the auction you just finished, showing: the Market Price, the Resale Value, the highest bidder's profit or loss, your profit or loss, your Cash Balance entering the period, and your current Cash Balance. Towards the bottom of the screen, you will see your signal, the signal of the participant who submitted the highest bid, and the signals of all buyers in your market. When all participants have clicked Continue, we proceed to the next period.

11. We will start with three or four practice "dry runs" that do not count towards your earnings, at which point we will stop and answer any additional questions.

Are there any questions? 


\section{Auction Instructions for $F P$ Treatment}

1. We will now create a market in which you will act as buyers of a fictitious commodity in a sequence of trading periods. A single unit of the commodity will be auctioned off in each trading period. There will be several trading periods.

2. At the start of each period, participants are randomly placed into "markets" containing six (6) participants. If the number of available participants is not an exact multiple of six, there will be a small number of participants that are not placed in a market and who will sit out until the next period.

The random assignment of participants to markets will be done separately and independently for each period. This means that the chances that you and any given other participant are in the same market in the current period do not depend on whether the two of you were in the same market in previous periods. Rarely, this randomization procedure can have the same participant sit out for two or more consecutive periods.

3. Your task is to bid for the commodity in competition with the other five buyers in your market. In each period, the computer will select a RESALE VALUE for the unit being auctioned. This indicates the value to you of purchasing the unit in your market. This value may be thought of as the amount you would receive if you were to resell the unit. The process of determining resale values and your signals regarding resale values will be described in Sections 6 and 7 below.

4. In each period, in the middle of the computer screen, you will see two rectangular boxes. You will be asked to type a number between 0 and 250 into the first box, which will be referred to as your bid for that period. Your bid should be an integer. To avoid possible typing mistakes, you will also be asked to confirm your bid by typing the same number into the second box. When you have entered your bid in both boxes, please click on the Continue button.

After everyone in your market has submitted their bids, the results of the market will be displayed. The participant in each market who submits the highest bid will be the one to purchase the unit, and the highest bid will be the Market Price for that period.

In the event two or more participants in the same market each submit the highest bid (i.e., a tie), one of the tying participants will be chosen at random to purchase 
the unit at that Market Price.

5. Those participants that do not purchase the item in a given period receive a Profit of zero for that trading period. The participant that purchases the item receives a Profit given by

$$
\text { Profit }=\text { Resale Value }- \text { Market Price }
$$

Profits earned during a trading period will be added to the purchaser's Cash Balance, and losses incurred will be subtracted from the purchaser's Cash Balance. Remember, your goal should be to maximize your profits, not the number of times you outbid the other participants.

If your Cash Balance falls below zero, you will not be allowed to continue participating. However, you are permitted to bid in excess of your Cash Balance in any given period.

6. For each market, the Resale Value will be a randomly drawn number between $25 \mathrm{ECU}$ and $225 \mathrm{ECU}$. Any value within this range has an equally likely chance of being drawn, and all randomizations are done all over again for each trading period.

7. Participants are NOT told the Resale Value in their market. However, at the beginning of each trading period, each participant will receive a Signal (which may be regarded as an estimate), that may provide information about the Resale Value in her/his market. Your signal will be randomly chosen between: a lower bound equal to the Resale Value minus 24, and an upper bound equal to the Resale Value plus 24. For example, if the Resale Value is 75 , then every participant in this market will receive a signal that is between 51 and 99. All signals in this interval are equally likely to be received, and a separate (and independent) randomization is done for each participant. That is, although all participants in the same market will face the same Resale Value, their signals that are generated in the way we have just described will usually be different.

Notice that you might receive a signal below 25 ECU or above 225 ECU. There is nothing strange about this; it just indicates that the Resale Value is either close to 25 ECU or close to 225 ECU.

8. Your signal will be displayed on your screen above the Bid Box and the Confirmation Box. This signal is strictly private information and is not to be revealed to anyone else. You are not to look at anyone else's screen or speak to any other 
participant while the experiment is in progress. This is important to the validity of the study.

9. As we mentioned earlier, Resale Values are determined randomly and independently from period to period. As such, a high value in one period tells you nothing about whether it might be high or low in the next period. Since a similar independent random process determines the signals, your signal in one period tells you nothing about signals or the Resale Value in later periods.

10. Information on the Computer Screen. At the beginning of each period, the top of the computer screen will show your ID number, your current Cash Balance, and the period number. In the middle of the screen, you will see your signal and the only possible Resale Values consistent with your signal. When everyone has clicked the Continue button, you will see a screen with the Bid Box and the Confirmation Box. To the right of these boxes will appear the Continue button, and above these boxes your signal for that period will be displayed.

After each trading period is over, you will see a screen that summarizes the auction you just finished, showing: the Market Price, the Resale Value, the highest bidder's profit or loss, your profit or loss, your Cash Balance entering the period, and your current Cash Balance. Towards the bottom of the screen, you will see your signal, the signal of the participant who submitted the highest bid, and the signals of all buyers in your market. When all participants have clicked Continue, we proceed to the next period.

11. We will start with three or four practice "dry runs" that do not count towards your earnings, at which point we will stop and answer any additional questions.

Are there any questions? 


\section{Auction Instructions for $A D^{P V}$ Treatment}

(instructions for $S D^{P V}$ and $F P^{P V}$ treatments available upon request)

1. We will now create a market in which you will act as buyers of a fictitious commodity in a sequence of trading periods. A single unit of the commodity will be auctioned off in each trading period. There will be several trading periods.

2. At the start of each period, participants are randomly placed into markets containing six (6) participants. If the number of available participants is not an exact multiple of six, there will be a small number of participants that are not placed in a market and who will sit out until the next period. The random assignment of participants to markets will be done separately and independently for each period. This means that the chances that you and any given other participant are in the same market in the current period do not depend on whether the two of you were in the same market in previous periods. Rarely, this randomization procedure can have the same participant sit out for two or more consecutive periods.

3. Your task is to bid for the commodity in competition with the other five buyers in your market. In each period, the computer will select your PRIVATE VALUE for the unit being auctioned. This indicates the value to you of purchasing the unit in your market. This value may be thought of as the amount you would receive if you were to resell the unit back to us. The process of determining private values will be described in Sections 6 and 7 below.

4. In each period, in the middle of the computer screen, you will see a rectangular clock displaying a price in ECUs, which we refer to as the Clock Price. In each new period, the market will begin with the clock displaying a Clock Price of 250 ECU. Then, after the market begins, for every half-second that passes, the Clock Price will decrease by 1 ECU. To express your willingness to purchase the unit at the current Clock Price, you must click the button labeled Purchase located beside the clock. The Clock Price at which you click Purchase will be referred to as your bid.

The clock will continue to tick down until the first moment that one of the participants in your market clicks Purchase. At this point, the clock will stop, and the participant who clicked Purchase will be the one to purchase the unit. The price displayed as the Clock Price at the time when that participant clicked Purchase will be the Market Price for that period. 
In the event two or more participants in the same market click the Purchase button at the same price (i.e., a tie), one of the tying participants will be chosen at random to purchase the unit at that Market Price.

If no participant in a given market has clicked Purchase when the Clock Price reaches zero, then no participant in that market will purchase the unit of the commodity.

5. Those participants that do not purchase the item in a given period receive a Profit of zero for that trading period. The participant that purchases the item receives a Profit given by

$$
\text { Profit }=\text { Private Value }- \text { Market Price }
$$

Profits earned during a trading period will be added to the purchaser's Cash Balance, and losses incurred will be subtracted from the purchaser's Cash Balance. Remember, your goal should be to maximize your profits, not the number of times you outbid the other participants.

If your Cash Balance falls below zero, you will not be allowed to continue participating. However, you are permitted to bid in excess of your Cash Balance in any given period.

6. For each market, we will first draw a number, which will be the SEED that helps us determine the Private Values of the participants in that market (to be explained below). The Seed will be a randomly drawn number between 25 ECU and 225 ECU. Any value within this range has an equally likely chance of being drawn, and all randomizations are done all over again for each trading period.

7. Participants are not told the Seed in their market. However, your Private Value will be randomly chosen between: a lower bound equal to the Seed minus 24, and an upper bound equal to the Seed plus 24. For example, if the Seed drawn happens to be 75 , then the Private Values of each participant in this market will be between 51 and 99. All Private Values in this interval are equally likely to be received, and a separate (and independent) randomization is done for each participant. That is, although all participants in the same market will have the same Seed, their Private Values that are generated in the way we have just described will be different. Notice that you might receive a Private Value below 25 ECU or above 225 ECU. There is 
nothing strange about this; it can happen if the Seed is either close to 25 ECU or close to $225 \mathrm{ECU}$.

8. Your Private Value will be displayed on your screen above the clock. This Private Value is strictly private information and is not to be revealed to anyone else. You are not to look at anyone else's screen or speak to any other participant while the experiment is in progress. This is important to the validity of the study.

9. As we mentioned earlier, Seeds are determined randomly and independently from period to period. As such, a high value in one period tells you nothing about whether it might be high or low in the next period. Since a similar independent random process determines the Private Values, your Private Value in one period tells you nothing about the Private Values in later periods.

10. Information on the Computer Screen. At the beginning of each period, the top of the computer screen will show your ID number, your current Cash Balance, and the period number. In the middle of the screen, you will see your Private Value. When everyone has clicked the Continue button, you will see a screen with the clock showing the initial Clock Price of 250 ECU. To the right of the clock will appear the Purchase button, and above the clock your Private Value for that period will be displayed. The auction will begin soon after seeing this screen, so you should plan your strategy when you first see your Private Value. After each trading period is over, you will see a screen that summarizes the auction you just finished, showing: the Market Price, the Private Value of the highest bidder, the highest bidder's profit or loss, your Cash Balance entering the period, and your current Cash Balance. Towards the bottom of the screen, you will see your Private Value, the Private Value of the participant who submitted the highest bid, the Private Values of all participants in your market, and the Seed in your market. When all participants have clicked Continue, we proceed to the next period.

11. We will start with three or four practice "dry runs" that do not count towards your earnings, at which point we will stop and answer any additional questions.

Are there any questions? 
Screen Shot from Card Tasks, Question 2

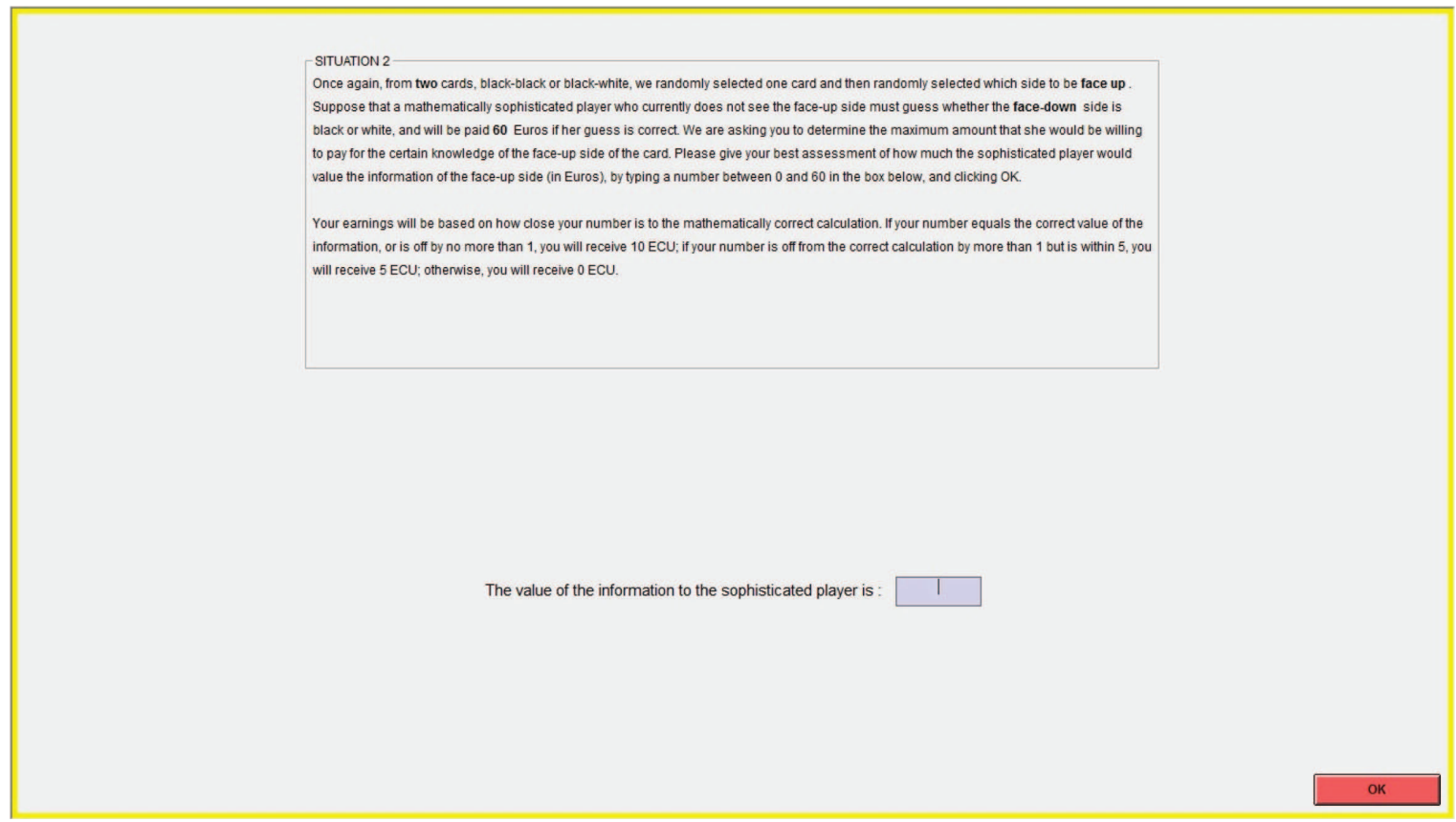


Screen Shot from $A D$ Auction

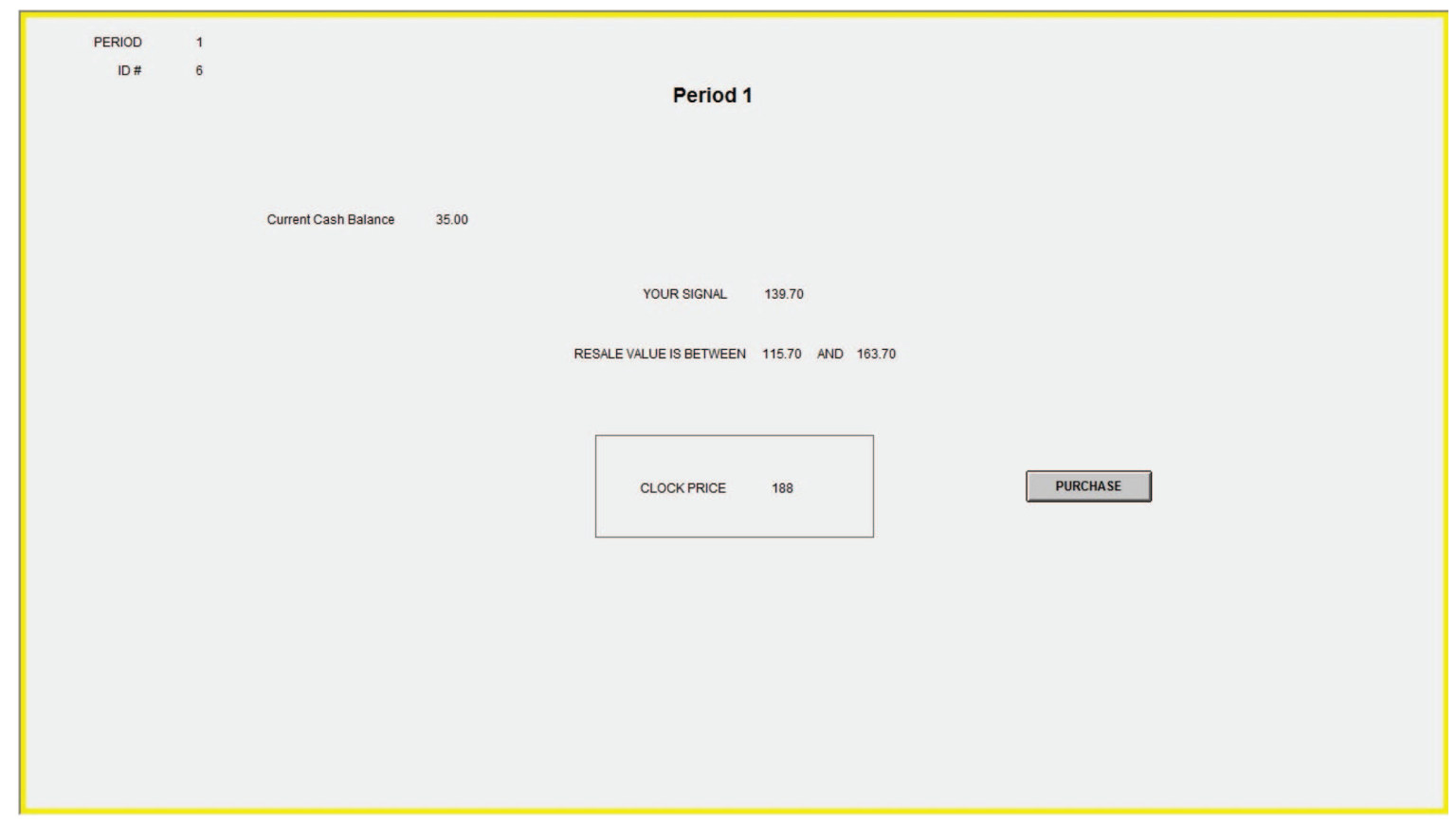


Screen Shot from FP Auction

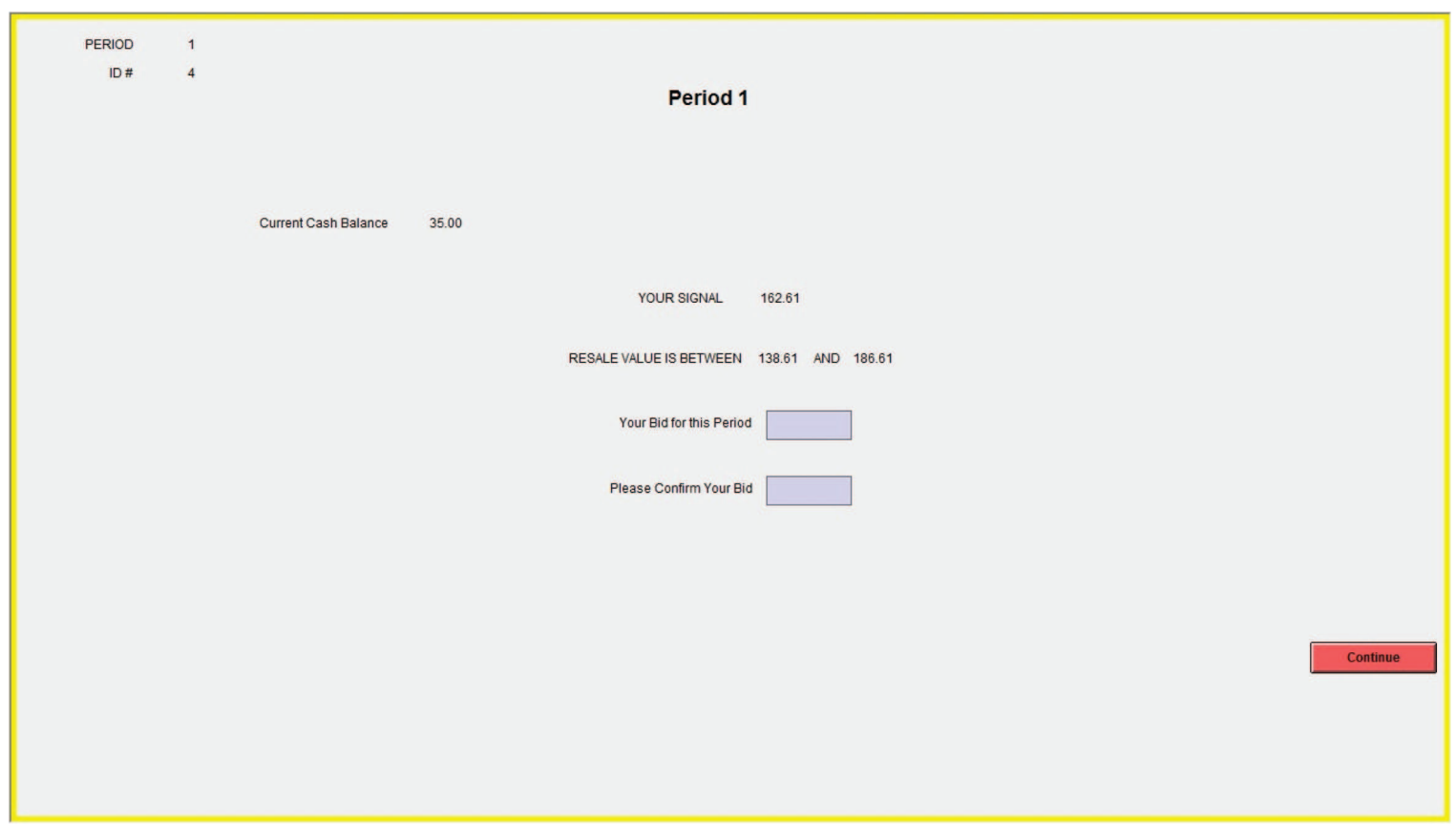


Screen Shot from $S D^{P V}$ Auction

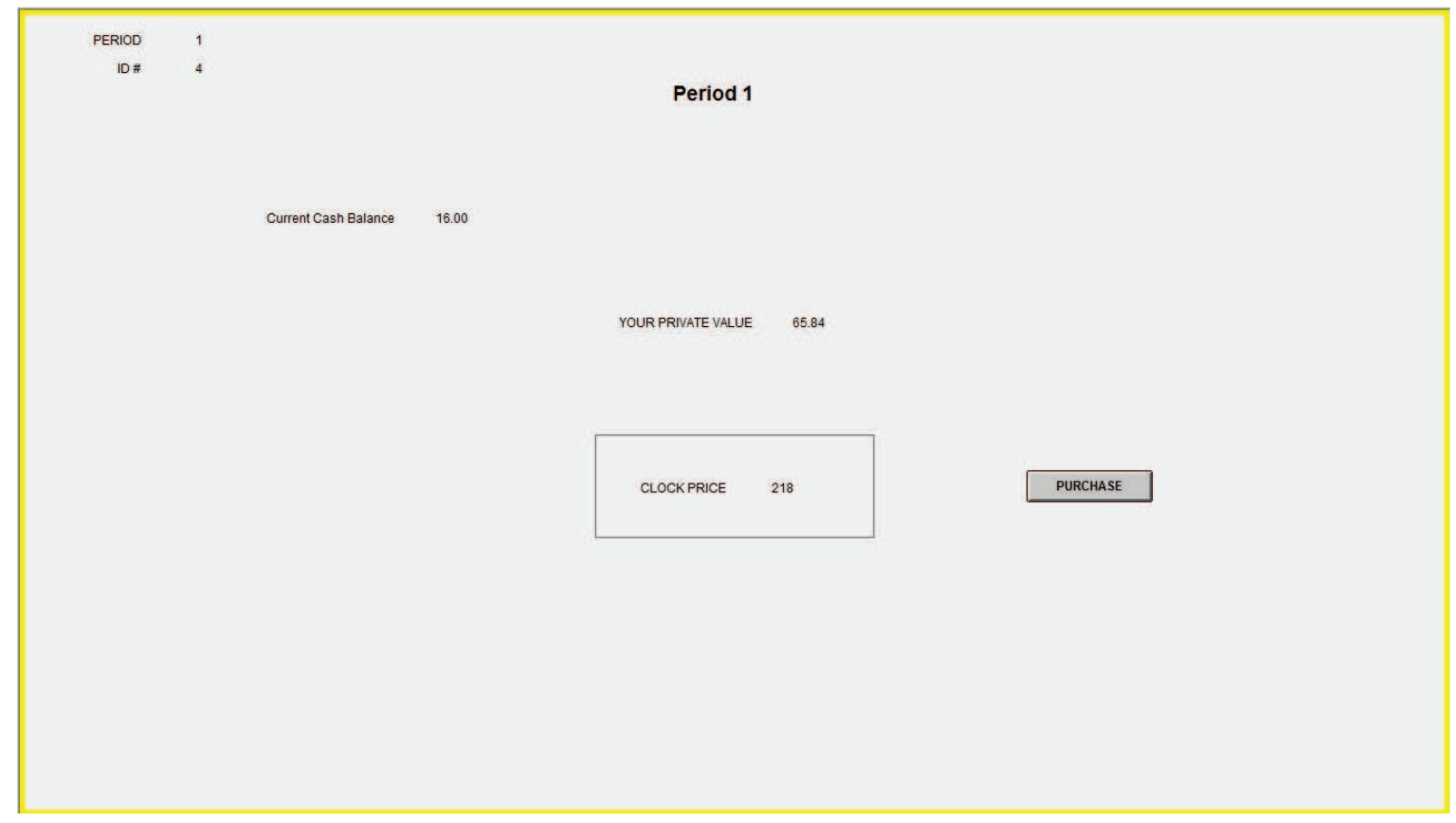

